\title{
CIDADES MÉDIAS NA AMAZÔNIA ORIENTAL

\author{
Das Novas Centralidades \\ à Fragmentação do Território
}

\section{Saint-Clair Cordeiro Da Trindade Júnior}

R E S U M O O artigo apresenta elementos da centralidade urbano-regional de cidades médias na Amazônia brasileira e discute o papel desse tipo de cidade em um contexto de reestruturação territorial. Para efeitos de análise considera a diferença conceitual entre "centro" $e$ "centralidade", assim como entre "fluxos" " "fixos". As referências empíricas da análise são duas cidades situadas na Amazônia Oriental - Marabá e Santarém. O estudo faz uma abordagem a propósito da importância dessas cidades para a produção do espaço regional e considera elementos históricos da formação territorial da Amazônia brasileira, assim como dados estatísticos e informaçôes documentais sobre essa regiāo e seu processo de urbanização. Ao final é destacado o papel da centralidade politica desempenhado pela cidade média na Amazônia em um contexto regional de rearranjo espacial, de emergência de novos interesses regionais e de propostas de divisão política do território.

P A L A V R A S - C H A V E Cidades médias; Amazônia Oriental; centralidade; divisão territorial.

\section{INTRODUÇÃO}

O quadro regional da Amazônia brasileira das últimas décadas nos faz concluir pela existência de uma nova dinâmica de urbanização que toma forma difusa e diversa na região. Há uma mudança no padrão de organização do espaço que desemboca, igualmente, em uma maior complexidade relacionada não só às formas das cidades, como também aos seus conteúdos, confirmando o processo diferenciado de produção do espaço.

Evidentemente que não se tratam de tipos isolados, mas, sobretudo, de expressões da urbanização que se combinam dentro de um mesmo subespaço, ou que acabam por revelar, em um mesmo ambiente urbano, faces diferenciadas da dinâmica econômica, política e cultural em curso no plano regional. Tal complexidade é fruto de um processo de transformação recente, que provocou profundas alteraçōes na paisagem urbana, mas que também nos revela resíduos de uma urbanização anterior que não foi definitivamente aniquilada.

A reestruturação da rede urbana e os novos papéis conferidos às cidades confirmam o perfil de uma nova estrutura produtiva, do mercado de trabalho e da importância política desses núcleos urbanos na Amazônia, o que implica, necessariamente, na ruptura de antigos padrões de organização espacial. Isso ocorre pelo caráter disseminado e pulverizado em que ocorreram os investimentos econômicos e as ações governamentais na região com a abertura da fronteira econômica desde a segunda metade do século XX.

Em que pese o grau elevado de urbanização da população, acima de $70 \%$ do contingente total de habitantes da região, as políticas de desenvolvimento parecem ter assumido 
10 presente trabalho contou com o apoio financeiro do CNPq (Conselho Nacional de Desenvolvimento Científico e Tecnológico), através dos projetos de pesquisa "Cidades médias na Amazônia: novos agentes econômicos e novas centralidades urbano-regionais no sudeste paraense" e "A cidade e o rio na Amazônia: mudanças e permanências face às transformações sub-regionais".

C I D A D E S M É D I A S N A A M A Z Ô N I A O O I E N T A L

um perfil notadamente não urbano. $\mathrm{Ou}$, quando se preocupam com essa dimensão da realidade regional, tratam-na como se fosse de uma natureza notadamente metropolitana. De maneira geral, entretanto, é recorrente a leitura da realidade regional como se as cidades não assumissem tanta importância, ou ainda, como se diferentes tipos e níveis de cidades não compusessem a urbanodiversidade regional, termo aqui utilizado para identificar as diferentes e plurais realidades urbanas da região.

De forma diferenciada, busca-se aqui trilhar um caminho em que seja possível falar de uma Amazônia urbana e, mais do que isso, de uma Amazônia onde a diversidade de pequenas e médias cidades desperte atenção na compreensão do atual quadro regional. Particularmente, na presente análise, ${ }^{1}$ pretende-se contribuir com conhecimentos a respeito deste último perfil de cidades, as cidades médias, que passaram a ter importância mais recentemente, inclusive do ponto de vista político, dentro da estrutura urbana regional. Esse empreendimento tem como base de reflexão as cidades de Marabá e Santarém, localizadas no Estado do Pará, na Amazônia Oriental brasileira, discutindo-se elementos da centralidade urbana nelas presentes.

A noção de centralidade aqui tratada busca ultrapassar a dimensão econômica dos fluxos que definem a importância das cidades médias. Nessa perspectiva, alcança também a noção de centralidade política, que, na presente discussão, sugere-se fazer parte da caracterização dessas cidades, quando as mesmas assumem a condição de centros urbanos sub-regionais em face do processo de reestruturação da rede urbana amazônica.

\section{A PRODUÇÃO DO ESPAÇO REGIONAL AMAZÔNICO E A IMPORTÂNCIA DAS CIDADES MÉDIAS}

Para o estudo das cidades médias, a relação das mesmas com a região se coloca como de extrema importância dado o seu caráter definidor da dinâmica urbana e do padrão de organização interna por elas apresentado. Nesse aspecto, acompanhando o raciocínio de Villaça (1998), diferentemente dos estudos metropolitanos, em que o deslocamento e a localização da força de trabalho no interior do espaço urbano definem, em sua maior parte, a dinâmica urbana, nas cidades médias essa importância possui um menor peso quando comparada à circulação de mercadorias em geral (capital constante, energia, informaçóes etc.) no contexto regional; daí o estudo da cidade média ser também e, ao mesmo tempo, um estudo de uma dada dinâmica sub-regional. Os exemplos de Marabá e de Santarém, no Estado do Pará, tendem a ratificar essa proposição.

A abordagem sugere também como pressuposto de análise a diferenciação entre cidade de porte médio, cidade intermediária e cidade média. No primeiro caso, considera-se o patamar populacional para reconhecer tão simplesmente o tamanho demográfico das cidades. As cidades intermediárias, por sua vez, são definidas tendo em vista sua posição relativa e intermediária (entre as pequenas cidades e as metrópoles regionais), independentemente de sua expressividade político-econômica no contexto hierárquico de uma rede urbana. São noções, portanto, que se diferenciam daquela que identifica o que seja a cidade média. Esta última leva em conta a importância sub-regional apresentada por uma dada cidade intermediária, ipso facto, pelas fortes centralidades que aí se materializam por meio de fluxos, a ponto de contribuírem significativamente para o ordenamento do espaço regional em que se inserem. 
Em consequência, são consideradas cidades médias aquelas que assumem um determinado papel na estrutura urbana regional como centro sub-regional, não sendo simplesmente centros locais, mas núcleos urbanos com capacidade de polarizar e influenciar um número significativo de cidades menores e articular relaçôes de toda ordem. Funcionam, assim, como anteparos e suportes às metrópoles regionais, não compondo junto com estas uma unidade funcional contínua e/ou contígua (Sposito, 2001b).

Com inspiração também no raciocínio da mesma autora, consideramos que, não obstante as cidades médias possam ser reconhecidas como intermediárias, tais definições não são intercambiáveis. As cidades intermediárias são aquelas que se colocam em um intervalo da hierarquia urbana entre as principais cidades regionais e as cidades locais, podendo ou não assumir importância regional. Da mesma forma, existem centros urbanos de porte médio que não são cidades médias por integrarem áreas metropolitanas. Há, ainda, cidades que, mesmo não atingindo o porte médio, assumem o papel de centros urbanos regionais, alçando-se, portanto, à condição de cidade média (Trindade Jr.; Pereira, 2007).

Como cidades médias, Marabá e Santarém, na Amazônia Oriental, chamam atenção pelo fato de desempenharem funções que servem de mediação entre as pequenas cidades da região e as metrópoles regionais e extrarregionais. Nessa condição, definem seus dinamismos em função da forte centralidade exercida em determinado contexto sub-regional, fato este que nos leva à compreensão da noção de centralidade. Para Sposito (2001a), é preciso estabelecer a diferença entre centro e centralidade, sendo o primeiro definido por aquilo que Santos (1996) considerou como sistema de fixos (o que se localiza) e o segundo, também denominado por Santos (1996), como sistema de fluxos (o que circula). Assim, a localização, sob a forma de concentração de atividades comerciais e de serviços, e, portanto, de fixos, revela o que se considera como central, ao passo que o movimento, ou seja, os fluxos, institui o que se mostra como centralidade. Tratam-se, na verdade, de duas experiências da realidade urbana que articulam, respectivamente, com pesos diferenciados, a dimensão espacial e temporal desses espaços (Sposito, 2001a).

Para a realidade aqui tratada, a referência ao sistema de fixos se faz importante, mas é na definição dos fluxos que se pode reconhecer o perfil de cidades médias assumidas por Marabá e Santarém ao longo da formação territorial amazônica. Portanto, não é exatamente a densidade dos fixos que define a importância dessas cidades nos últimos anos na região, mas principalmente a centralidade - os fluxos -, que muitas vezes intensifica o uso dos fixos disponíveis. Neste caso, a centralidade passa a ser compreendida pela convergência de fluxos e pelo caráter centrípeto por eles exercido em direção a um determinado ponto da rede urbana, devido a uma dada disponibilidade de infraestrutura e a uma relativa densidade técnica, de atividades econômicas, sociais e políticas que nesse ponto se concentram (Trindade Jr.; Ribeiro, 2008).

No caso amazônico, a urbanização guarda, em grande parte, profunda relação com uma lógica intencional do Estado (Machado, 2000), principalmente a partir da década de 1960, quando o índice anual de urbanização se intensificou. O controle da terra, a política de migração induzida e financiada pelo poder público e o incentivo a grandes empreendimentos, asseguraram o desenvolvimento da fronteira urbana. ${ }^{2}$ Esta última, segundo Becker (1990) e Machado (2000), funcionou como recurso estratégico para a rápida ocupação da região, antes mesmo da implantação de projetos de produção agrícola, pecuarista, energética, mineral e/ou industrial. É uma realidade, assim, que reproduz características de fronteira econômica, representando, para as empresas e investidores
2 Base logística para o projeto de rápida ocupação da região, implicando em proliferação e crescimento de cidades, bem como em difusão do modo de vida urbano (Becker, 1990). 
capitalistas, um espaço de valor onde se podem implantar rapidamente novas estruturas produtivas e de circulação, servindo, ainda, como reserva mundial de matérias-primas.

Desse modo, as cidades tornaram-se bases logísticas para as políticas de desenvolvimento pensadas para a região e para a ressocialização da população migrante (Becker, 1990). Essas políticas definiram um conjunto de elementos novos na urbanização da região, cujas características, para as décadas de 1970 e 1980, podem ser elencadas da seguinte forma: a valorização dos centros localizados às margens das rodovias; a reprodução de pequenos núcleos dispersos vinculados à mobilidade do trabalho; a retração de núcleos antigos, que ficaram isolados à margem das novas formas de circulação; a implantação de franjas urbanas avançadas, correspondentes às cidades das companhias; e a concentração nas capitais estaduais (Becker, 1990; Corrêa, 1987; Vicentini, 1994). Esses elementos definiram uma urbanização polimorfa e desarticulada, atribuída a diferentes formas de interações socioespaciais e a diversas formações microssociais híbridas (Browder; Godfrey, 1997).

Outros estudos indicam novas tendências, não presentes no passado (Quadro 1). De um lado, o reforço da metrópole dispersa como parte do processo de "metropolização", de outro, a proliferação de pequenas cidades e o crescimento dinâmico de novos núcleos urbanos - as "cidades médias" - que, na Amazônia, cumprem o papel de centros regionais (Ribeiro, 1998; Machado, 2000). São exemplos desse nível de cidades, as capitais de alguns estados, como Rio Branco (no Estado do Acre), Porto Velho (no Estado de Rondônia), Boa Vista (no Estado de Roraima), e outras cidades, que não são capitais, mas que se alçam à categoria de cidades médias dada à importância na nova dinâmica econômica regional. É o caso, por exemplo, de Marabá, Santarém e Castanhal, no Estado do Pará, e de Imperatriz, no Estado do Maranhão; todas integrantes da Amazônia Oriental, onde a expansão do fenômeno urbano no território é mais intenso e bastante diferenciado, quando comparado à Amazônia Ocidental.

Quadro 1 - Amazônia: a rede urbana em dois momentos

\begin{tabular}{|l|l|}
\hline Forma Dendrítica (Antes de 1960) & Forma Anastomosada (Após 1960) \\
\hline Atividades econômicas tradicionais & Frentes econômicas e de modernização \\
\hline Circulação fluvial e ferroviária & Circulação multimodal: destaque às rodovias \\
\hline Cidades dos notáveis: pequenas e semelhantes & Cidades híbridas: dos “notáveis” e econômicas \\
\hline Cidade primaz & Difusão do fenômeno de metropolização \\
\hline Concentração econômica & Desconcentração econômica \\
\hline Pouco destaque às cidades intermediárias & Importância das cidades médias \\
\hline
\end{tabular}

Elaboração: Saint-Clair C. da Trindade Júnior.

Tanto as médias quanto as pequenas cidades apresentaram interessantes índices de crescimento populacional nas últimas décadas, algumas delas, inclusive, superiores aos grandes centros urbanos. Tais cidades detêm, segundo dados oficiais, grande parte da população regional. Entretanto, a expansão da fronteira econômica não se deu de maneira igual quando consideramos a especificidade das sub-regióes. A Amazônia Oriental, em particular, tende a acompanhar um processo que já vem sendo verificado há algum tempo no restante do território brasileiro. Conforme nos mostra Santos (1993), as grandes cidades já apresentam taxas de crescimento econômico menores do que suas respectivas 
regiōes, repercutindo no maior dinamismo e importância dos outros níveis de cidades, como as cidades médias, conforme também acontece na Amazônia Oriental.

\section{FLUXOS ECONÔMICOS E NOVAS CENTRALIDADES}

As cidades selecionadas como exemplos para a presente análise, assumidas aqui como representativas de suas respectivas sub-regióes, são classificadas, para efeitos de discussão, como centros urbanos regionais. No caso de Marabá, trata-se de uma cidade que vem sendo lócus de grandes investimentos na região, pela importância produtiva, comercial, distribuição de serviços e liderança política no sul/sudeste paraense, tornando-se, com isso, uma das mais importantes no ranking econômico do Estado do Pará. Constitui-se também um importante nó da rede urbana, viária e elétrica da Amazônia Oriental, e com destaque para a sua base produtiva assentada na agropecuária, na indústria mínerometalúrgica e no extrativismo vegetal e mineral (Tavares, 1999).

Há, nesse caso, uma trajetória histórica a ser considerada no seu processo de formação e de dinamização, que se deu a partir de frentes pioneiras de atividades extrativas, minerais e vegetais, responsável pela formação de oligarquias tradicionais ligadas a atividades como a exploração da castanha-do-pará (Emmi, 1987). Mesmo o declínio da atividade gomífera na Amazônia afetou apenas parcialmente a sub-região onde se localiza Marabá. A exploração de produtos como a castanha-do-pará no vale do Tocantins-Itacaiúnas, possibilitou certo dinamismo a essa cidade, reafirmando seu papel como sub-centro com o processo de integração da região, que se consolidou a partir da década de 1960, quando se tornou o principal centro urbano de apoio à colonização agrária. Nesse contexto, foi definida, pelas políticas territoriais do governo federal, como rurópolis, o nível mais elevado de cidade, pensado a partir do modelo de urbanismo rural do Instituto Nacional de Colonização e Reforma Agrária (Incra), que orientava o processo de ocupação ao longo das rodovias, como no caso da Transamazônica,

Hoje, além de sua importância econômica para o sul/sudeste paraense, é notável seu papel como entroncamento aeroviário e rodoferroviário para as cidades menores de sua sub-região. Ademais, a articulação de Marabá com regiōes vizinhas, inclusive fora da Amazônia, por meio das novas vias de circulação, fez da mesma uma das principais cidades da Amazônia brasileira, após os maiores centros urbanos regionais. Assumem importância, nesse caso, as rodovias Transamazônica, PA-150, BR-222 e a Estrada de Ferro Carajás, que articulam a Amazônia brasileira a diversos municípios considerados espaços de novas oportunidades econômicas e de investimentos capitalistas.

Nesse contexto, de novas redes de circulação, o rio Tocantins, de fundamental importância na formação da sub-região e da cidade de Marabá, tem seu papel econômico relativizado em face das novas estratégias de ordenamento territorial. O modelo de ocupação assentado no tripé "rodovia - terra-firme - subsolo" (Porto-Gonçalves, 2005) parece confirmar a importância dessa cidade para a nova configuração sub-regional e para uma tendência de "negação do rio" face às novas frentes de expansão econômica.

Para o caso de Santarém, conforme os estudos de Pereira (2004), os fluxos de mercadoria e pessoas das capitais estaduais, notadamente Belém e Manaus, como também de outros centros urbanos da região, têm naquela cidade uma referência nodal. Tal importância se projeta, seja do ponto de vista da circulação aérea - o aeroporto de Santarém é o 
segundo maior em movimento de passageiros do Estado do Pará -, seja do ponto de vista da circulação rodoviária (rodovia Cuiabá-Santarém articulada à Transamazônica) e fluvial (rio Amazonas e Tapajós). Neste caso, circulação rodoviária, aeroviária e hidroviária parece se complementar, em uma forma de organização do espaço um pouco diferenciada daquela verificada no sul/sudeste do Pará.

A articulação da cidade de Santarém se dá tanto com o Baixo Amazonas como também com o sudoeste paraense, consideradas aqui como parte de uma sub-região maior, o oeste do Pará, e, ainda, com a parte oriental do Estado do Amazonas. Esse papel foi construído ao longo de sua trajetória de formação territorial, como pode ser observado por seus antecedentes históricos. Desde o início do processo de colonização da região no século XVII, Santarém assumiu um importante papel na consolidação do novo povoamento regional. Isso se reafirma no século XIX, com a economia gomífera, e se ratifica com as políticas de integração regional e, mais recentemente, com a expansão da produção da soja em direção à rodovia Cuiabá-Santarém.

A exemplo de Marabá, e diferentemente de outras cidades ligadas à economia da borracha e que passaram por um período de estagnação com a queda dos preços do produto no mercado mundial, a existência de outras atividades na área de polarização de Santarém, como a produção de juta, praticada nas várzeas dos rios, fizeram com que essa cidade mantivesse um relativo dinamismo econômico, conferindo-lhe certo destaque na economia regional no período imediato pós-borracha (Corrêa, 1987) e mantendo esse destaque até os dias atuais.

Ainda de acordo com Pereira (2004), na divisão territorial do trabalho, o Município de Santarém é um dos mais novos polos produtores de soja da Amazônia, principalmente ao longo da BR-163 (Cuiabá-Santarém), e a sede municipal cumpre um importante papel no corredor de escoamento da produção de grãos da região central do Brasil, que do porto local de Santarém parte em direção aos Estados Unidos e Europa, devido à localização estratégica desta cidade em relação aos grandes centros consumidores de grãos exportados pelo Brasil. A farta disponibilidade de recursos naturais constitui outro fator de atração do grande capital. As grandes reservas florestais também têm sido alvos da ação de madeireiros, devido ao alto valor comercial e da variedade de espécies existentes, como já acontece em outros estados da Amazônia (Pereira, 2004).

A importância dessas duas cidades reflete, portanto, a dinâmica da sub-região nas quais se localizam, constituindo-se dentro desse quadro sub-regional (Quadro 2) os principais centros urbanos de dinamismo econômico. 
Quadro 2 - Marabá e Santarém e suas unidades sub-regionais

\begin{tabular}{|c|c|c|}
\hline $\begin{array}{l}\text { Unidades } \\
\text { Sub-Regionais }\end{array}$ & Sudeste do Pará & Baixo Amazonas \\
\hline $\begin{array}{l}\text { Principal cidade } \\
\text { (População) }\end{array}$ & Marabá (176.834 habitantes) & Santarém (134.258 habitantes) \\
\hline Localização & $\begin{array}{l}\text { Sul e sudeste do estado do Pará, vales do rio } \\
\text { Araguaia e do Tocantins e afluentes }\end{array}$ & $\begin{array}{l}\text { Baixo Amazonas e parte da área de } \\
\text { influência da rodovia BR-163 (Cuiabá- } \\
\text { Santarém) }\end{array}$ \\
\hline $\begin{array}{l}\text { Principais elementos } \\
\text { relacionados à formação } \\
\text { socioespacial }\end{array}$ & $\begin{array}{l}\text { Ocupada de forma mais intensa a partir da } \\
\text { exploração das drogas do sertão, teve sua dinâmica } \\
\text { reforçada posteriormente com a exploração do } \\
\text { caucho e da castanha, que contribuíram para } \\
\text { desterritorializar populaçôes tradicionais e formar } \\
\text { uma forte oligarquia da castanha, que perdurou } \\
\text { até a primeira metade da década de } 1970 \text {. } \\
\text { Com a expansão de frentes econômicas diversas } \\
\text { (madeireiras, agrícolas pecuaristas, minerais etc.) } \\
\text { novos agentes se fizeram presentes a partir da } \\
\text { década de 1960, formando uma região dinâmica do } \\
\text { ponto de vista econômico e de intensos conflitos } \\
\text { pela apropriação do território e de seus recursos. } \\
\text { Grande presença do Estado através da implantação } \\
\text { de infraestrutura, políticas migratórias e incentivos } \\
\text { fiscais. }\end{array}$ & $\begin{array}{l}\text { Área de antiga colonização com importância } \\
\text { na extração de produtos da floresta e na } \\
\text { agricultura, especialmente a juta, e de } \\
\text { expansão recente de frentes econômicas que } \\
\text { provocaram a reorganização capitalista do } \\
\text { espaço de caráter pontual e linear. } \\
\text { Presença de frentes de modernização } \\
\text { recente que incluem grandes projetos de } \\
\text { exploração mineral, rodovias, hidrelétrica } \\
\text { e infraestrutura portuária definiram uma } \\
\text { nova ordem territorial que combina açôes } \\
\text { estatais com ordenamento espontâneo com } \\
\text { a presença de agentes econômicos diversos. }\end{array}$ \\
\hline $\begin{array}{l}\text { Papel na divisão } \\
\text { territorial do trabalho }\end{array}$ & $\begin{array}{l}\text { A importância do diamante e da castanha no } \\
\text { passado cede lugar nos dias atuais à forte presença } \\
\text { de atividades mais modernas como a agricultura, a } \\
\text { pecuária leiteira e de corte, e a exploração mineral; } \\
\text { atividades estas praticadas por agentes de pequeno, } \\
\text { médio e grande porte. }\end{array}$ & $\begin{array}{l}\text { Área com a presença de grandes projetos, } \\
\text { de atividades tradicionais e de atividades } \\
\text { recentes em expansão e consolidação, a } \\
\text { exemplo da agropecuária, notadamente a } \\
\text { expansão da soja, e da produção extrativa } \\
\text { vegetal e mineral. }\end{array}$ \\
\hline $\begin{array}{l}\text { Agentes } \\
\text { econômico- } \\
\text { políticos e } \\
\text { territorialidades }\end{array}$ & $\begin{array}{l}\text { Grande disputa pelo espaço, com conflitos de } \\
\text { territorialidade de caráter pontual ou ao longo } \\
\text { de linhas, decorrentes da expansão capitalista. } \\
\text { Movimento de criação do Estado de Carajás, } \\
\text { comandado especialmente por novos agentes } \\
\text { econômicos que referendam uma nova identidade } \\
\text { política, econômica e cultural em consolidação e } \\
\text { que vem sendo utilizada pelos diversos atores como } \\
\text { demarcatória de uma nova unidade territorial com } \\
\text { intençôes separatistas. }\end{array}$ & $\begin{array}{l}\text { Presença de elite tradicional e de espaço de } \\
\text { conflitos entre formas novas de apropriação } \\
\text { do território decorrente de novos agentes } \\
\text { (grandes empresas, colonos e migrantes } \\
\text { sem capital, Estado etc.) e de formas } \\
\text { tradicionais de apropriação do território e } \\
\text { de seus recursos (oligarquias, populaçōes } \\
\text { tradicionais etc.). Presença de relativa } \\
\text { identidade territorial que sustenta a criação } \\
\text { de um novo estado da federação a partir da } \\
\text { fragmentação do território paraense. }\end{array}$ \\
\hline
\end{tabular}

Fontes: GUERRA, G. A. D. “Apropriação, uso da terra e desenvolvimento territorial na Amazônia”. In: ROCHA, G. M.; MAGALHĀES, S. B; TELSSERENC, P. Territórios de desenvolvimento e ações públicas. Belém: Edufpa, 2009. p.185-205; MAGNANO, A. “A estrutura do espaço regional”. In: IBGE. Geografia do Brasil: região norte. Rio de Janeiro, 1989, v. 3, p.275-307.

A importância quanto ao repasse na arrecadação de impostos, ainda que inferior ao aglomerado metropolitano do qual fazem parte Belém e Ananindeua, colocam Santarém e Marabá entre os 10 (dez) municípios com maiores arrecadaçóes no conjunto de 144 (cento e quarenta e quatro) municípios de todo o Estado do Pará. 
Tabela 1 - Pará: Repasse em Reais da arrecadação do Imposto Sobre Circulação de Mercadorias e Serviços (ICMS) aos principais municípios - 20 Semestre de 2007

\begin{tabular}{|l|c|c|}
\hline Municípios & Total do Semestre & Quota-Parte (\%) \\
\hline Altamira & $1.331 .831,89$ & 1,65 \\
\hline Ananindeua & $3.438 .547,78$ & 4,26 \\
\hline Barcarena & $4.988 .315,80$ & 6,18 \\
\hline Belém & $16.409 .783,20$ & 20,33 \\
\hline Canaã dos Carajás & $1.234 .971,39$ & 1,53 \\
\hline Marabá & $4.407 .152,79$ & 5,46 \\
\hline Oriximiná & $2.421 .512,52$ & 3,0 \\
\hline Parauapebas & $7.522 .832,24$ & 9,32 \\
\hline Santarém & $2.025 .998,81$ & 2,51 \\
\hline Tucuruí & $3.858 .276,62$ & 4,78 \\
\hline
\end{tabular}

Fonte: Governo do Estado do Pará. Secretaria de Estado de Planejamento, Orçamento e Finanças, Diretoria do Tesouro Estadual, 2007. Obs.: Deduzidos 15\% de contribuição ao FUNDEF.

Tabela 2 - Pará - Repasse em Reais de Imposto Sobre Produtos Industrializados (IPI) aos principais municípios $-1^{\circ}$ Semestre de 2008

\begin{tabular}{|l|c|c|}
\hline Municípios & Total do Semestre & Quota-Parte (\%) \\
\hline Altamira & $189.048,52$ & 1,62 \\
\hline Ananindeua & $506.463,31$ & 4,34 \\
\hline Barcarena & $750.359,23$ & 6,43 \\
\hline Belém & $2.405 .117,23$ & 20,61 \\
\hline Canaã dos Carajás & $210.053,91$ & 1,80 \\
\hline Marabá & $682.675,20$ & 5,85 \\
\hline Oriximiná & $316.247,83$ & 2,71 \\
\hline Parauapebas & $1.051 .436,50$ & 9,01 \\
\hline Santarém & $268.402,21$ & 2,30 \\
\hline Tucuruí & $547.307,12$ & 4,69 \\
\hline
\end{tabular}

Fonte: Governo do Estado do Pará. Secretaria de Estado da Fazenda, Diretoria do Tesouro Estadual, 2008.

Poder-se-ia questionar se as outras cidades que apresentam melhor desempenho na arrecadação também não se caracterizariam como cidades médias, tal a importância econômica que possuem no espaço paraense. Na verdade, os municípios que apresentam melhores arrecadações no conjunto do Estado, ou integram a Região Metropolitana de Belém - caso de Belém e Ananindeua -, ou são sedes de importantes projetos econômicos. Diferentemente, Marabá, Santarém e Altamira justificam seu desempenho na arrecadação pela importância como centros urbanos sub-regionais, definindo significativos fluxos de pessoas, mercadorias e informações no contexto do espaço paraense e da Amazônia Oriental.

Daquelas cidades cujo papel da arrecadação está associado a um grande projeto, provavelmente apenas Tucuruí possa ser considerada uma cidade média, pelo papel que 
assume do ponto de vista econômico, notadamente da distribuição de bens e serviços, para um conjunto de municípios direta ou indiretamente afetados pelo grande empreendimento hidrelétrico ali construído.

As demais cidades, mesmo com forte dinamismo econômico assentado no grande empreendimento instalado, são de pequeno porte e/ou com bases logísticas urbanas bem definidas, que estabelecem relaçôes mais verticais (extrarregionais) que horizontais (dentro da própria região), e articulações muito mais organizacionais (corporativas) que orgânicas (relacionadas a vivências cotidianas) (Santos, 1996) com o restante do espaço paraense. Não são, portanto, centros regionais, mas verdadeiros enclaves urbanos no conjunto da rede urbana. Assim, mesmo com status econômico e equipamentos urbanos que as potencializam à condição de cidades médias, não definem polarizaçóes regionais significativas e não se constituem propriamente como centros de distribuição e oferta de bens e serviços, apresentando, portanto, frágeis centralidades econômicas. Isso mostra, inclusive, a insuficiência de considerarmos o dinamismo econômico como critério isolado para definir as cidades médias.

Em que pese a tendência, no Brasil, de associar as cidades médias à modernização econômica e à melhoria da qualidade de vida da população, é preciso considerar que determinados critérios relacionados diretamente ao padrão de vida da população residente não ajudam muito a reconhecer a centralidade dessas cidades e a identificá-las como centros urbanos regionais. Assim, associar a importância das cidades médias à melhoria da qualidade de vida parece induzir a equívocos, principalmente se considerarmos a diversidade territorial brasileira e amazônica e as especificidades dos centros urbanos regionais dentro dos diferentes contextos territoriais. É o que podemos concluir, por exemplo, se cotejarmos a situação de pobreza e renda (Tabela 3) e de saneamento básico (Tabela 4) das duas cidades amazônicas aqui exemplificadas com outras cidades de sub-regióes mais dinâmicas e consolidadas economicamente, como as do estado de São Paulo.

Tabela 3 - Pobreza e renda em municípios com sedes porte médio nos estados do Pará e de São Paulo - 2001

\begin{tabular}{|l|c|c|c|}
\hline Municípios & $\begin{array}{c}\text { Renda Média - Resp. } \\
\text { p/ Dom. (R\$) }\end{array}$ & $\begin{array}{c}\text { Proporção de } \\
\text { pobres (\%) }\end{array}$ & $\begin{array}{c}\text { Renda Per Capita } \\
\text { (R\$) }\end{array}$ \\
\hline PARAENSES & & & \\
\hline Marabá & 614 & 44,0 & 188,6 \\
\hline Santarém & 451 & 54,0 & 139,9 \\
\hline PAULISTAS & & & \\
\hline Presidente Prudente & 1.073 & 12,0 & 482,6 \\
\hline Sorocaba & 1.089 & 10,6 & 448,2 \\
\hline Marília & 979 & 11,5 & 421,2 \\
\hline Franca & 854 & 8,3 & 359,6 \\
\hline
\end{tabular}

Fonte: IPEA, FJP e PNUD apud Trindade Jr. e Pereira (2007) 
Tabela 4 - Acesso aos serviços de saneamento em municípios com sedes de porte médio nos estados do Pará e de São Paulo - 2000

\begin{tabular}{|l|c|c|}
\hline Municípios & Saneamento Adequado (\%) & Saneamento Inadequado (\%) \\
\hline PARAENSES & 15,6 & 29,4 \\
\hline Marabá & 20,0 & 28,5 \\
\hline Santarém & 93,4 & 1,8 \\
\hline PAULISTAS & 97,3 & 1,3 \\
\hline Marília & 94,6 & 1,5 \\
\hline Franca & 96,1 & 0,3 \\
\hline Presidente Prudente &
\end{tabular}

Fonte: Indicadores Sociais Municipais 2000 - Brasil apud Trindade Jr. e Pereira (2007)

Muito mais que definir a cidade média pelo seu patamar demográfico ou pelo seu grau de modernização, parece ser importante considerar o seu papel enquanto espaço relacional no contexto regional em que se insere. Nesse sentido, o papel das cidades médias na Amazônia sugere levar em conta a relação das mesmas em face dos novos processos que se desdobram no plano regional. Considerando Marabá e Santarém, constata-se que o perfil desse nível de cidades é bem diferenciado quanto às demais cidades de outras regiōes brasileiras. Tal diferenciação não se confirma apenas quanto ao patamar populacional, que nas cidades do centro-sul brasileiro é bem superior, mas igualmente no que diz respeito à capacidade de acumulação e de canalização de riquezas em comparação ao espaço metropolitano.

Assim, muito mais que definir um perfil de cidade moderna, que se caracteriza por melhor qualidade de vida, faz-se necessário reconhecer a centralidade dessas mesmas cidades. Isso se coloca, pois nem sempre tais cidades revelam uma possível incorporação dos processos de acumulação de capitais decorrentes dos investimentos realizados no contexto regional em que se inserem. Essa constatação nos induz a pensar, de fato, o que seja a cidade média na região amazônica. A nosso ver tais cidades são marcadas menos pela presença de fixos modernos, que pela presença de fluxos de mesma ordem.

Com essa preocupação, o estudo de Ribeiro (1998) arrolou importantes centros regionais no espaço amazônico que incluem as cidades aqui referenciadas. No tocante à distribuição de bens e serviços, Ribeiro (1998) identificou cinco níveis de centralidade. Dentre esses níveis, destacam-se as cidades de nível intermediário, que ocupam a segunda posição hierárquica em sua região e são representados por quinze centros que refletem a desigualdade socioespacial regional, subordinando-se, em sua maioria, àquelas cidades de primeiro nível (Belém, São Luís, Cuiabá e Manaus).

Tais cidades constituem importantes "nós" de distribuição de bens e serviços e podem ser identificadas por suas características distintas e particulares em: centros que apresentam traço da frente pioneira agropastoril e mineral; centros que estão situados nas bordas nordestinas no Estado do Maranhão; centros que fazem parte da Amazônia tradicional e seu sistema dendrítico-ribeirinho, geralmente antigos e revitalizados, aqui incluindo Santarém; e centros que margeiam as estradas, como é o caso de Marabá (Ribeiro, 1998). 
$\mathrm{Na}$ verdade, são os fluxos os responsáveis por garantir uma rede de relações horizontais e verticais que dão um novo sentido aos subespaços regionais como "nós" importantes de circulação de capitais, mercadorias, informações e pessoas em contextos de fronteiras de expansão econômicas e tecno-ecológicas (Becker, 2004), ou como centros difusores de "manchas pioneiras", ${ }^{3}$ conforme prefere denominar Huertas (2009), que reconhece dez centros que cumprem esse papel na Amazônia, dentre eles Marabá e Santarém (Quadro 3).

No caso de Santarém e Marabá, tratam-se de cidades mais antigas que passaram por um processo de revigoramento oriundo da valorização econômica de produtos econômicos locais e da abertura de rodovias de penetração. Por isso são núcleos mais consolidados e irradiadores de dinamismo econômico, que reafirmam a centralidade regional. Esta, por sua vez, está ancorada em fluxos centrípetos, fortemente definidos pela presença de funções terciárias ampliadas que incluem: abastecimento regular de combustível, comércio de insumos e máquinas agrícolas, empresas de geoprocessamento e licenciamento ambiental, linhas aéreas regionais, agências bancárias, recrutamento de mão de obra qualificada e representações de órgãos públicos relevantes (Huertas, 2009). Essa centralidade econômica aqui considerada, todavia, repercute também em outras dimensões da dinâmica regional, como as relaçôes de poder, definindo o papel político que passa a ser assumido por essas cidades médias no conjunto da rede urbana regional.
3 Para Huertas (2009), no período atual, constatam-se novas frentes de expansão que são comandadas por frentes antigas, onde algumas cidades se tornaram centros regionais relevantes ao longo das últimas quatro décadas. 0 autor denomina essas cidades de centros difusores, nas quais estão os centros subregionais, identificados aqui como cidades médias, que apresentam, no contexto regional, alta capacidade de fornecimento de ordens e serviços para os peque nos municípios que gravitam ao seu redor.

Quadro 3 - Amazônia: centros difusores da "mancha pioneira"

\begin{tabular}{|c|c|c|c|c|c|c|c|c|c|}
\hline \multirow[b]{2}{*}{ Municípios $^{(1)}$} & \multicolumn{2}{|c|}{ População } & \multicolumn{5}{|c|}{$\mathrm{PIB}^{(2)}(\mathrm{em}$ mil R\$) } & \multicolumn{2}{|c|}{ Estrutura Financeira $^{(3)}$} \\
\hline & Total & $\begin{array}{c}\text { Urbana } \\
(\%)\end{array}$ & VAA & VAI & VAS & IMP & $\mathrm{NOM}$ & $\begin{array}{l}\text { Agências } \\
\text { bancárias }\end{array}$ & $\begin{array}{l}\text { Total das } \\
\text { operaçóes } \\
\text { de créditos } \\
\text { (em mil R\$) }\end{array}$ \\
\hline $\begin{array}{l}\text { Santarém (PA) } \\
1661\end{array}$ & 262.538 & 70,96 & 94.786 & 177.552 & 858.027 & 136.173 & 1.266 .535 & 10 & 142.426 \\
\hline $\begin{array}{l}\text { Itaituba (PA) } \\
1935\end{array}$ & 94.750 & 68,06 & 39.871 & 68.813 & 250.013 & 31.331 & 390.028 & 05 & 43.745 \\
\hline $\begin{array}{l}\text { Altamira (PA) } \\
1911\end{array}$ & 77.439 & 80,43 & 47.813 & 47.956 & 242.629 & 29.845 & 368.243 & 06 & 83.260 \\
\hline $\begin{array}{l}\text { Marabá (PA) } \\
1913\end{array}$ & 168.020 & 79,98 & 68.144 & 711.182 & 1.041 .289 & 259.224 & 2.079 .838 & 10 & 193.821 \\
\hline $\begin{array}{l}\text { Humaitá (AM) } \\
1890\end{array}$ & 32.796 & 73,15 & 23.725 & 10.413 & 82.426 & 8.763 & 125.326 & 03 & 11.280 \\
\hline $\begin{array}{l}\text { Vilhena (RO) } \\
1977\end{array}$ & 53.598 & 94,41 & 113.889 & 157.943 & 415.710 & 109.738 & 797.280 & 06 & 101.510 \\
\hline $\begin{array}{l}\text { Sinop (MT) } \\
1979\end{array}$ & 74.831 & 90,48 & 114.233 & 261.460 & 611.400 & 141.430 & 1.128 .523 & 09 & 401.025 \\
\hline $\begin{array}{l}\text { Alta Floresta } \\
\text { (MT) } 1914\end{array}$ & 46.982 & 79,36 & 78.227 & 75.879 & 197.899 & 35.702 & 387.707 & 05 & 125.609 \\
\hline $\begin{array}{l}\text { Barra do Garças } \\
\text { (MT) } 1914\end{array}$ & 52.092 & 91,12 & 46.002 & 135.119 & 285.935 & 52.871 & 519.927 & 06 & 277.533 \\
\hline $\begin{array}{l}\text { Redenção (PA) } \\
1982\end{array}$ & 63.251 & 94,25 & 43.158 & 97.352 & 235.276 & 35.385 & 411.171 & 06 & 102.096 \\
\hline
\end{tabular}

Fonte: Instituto Brasileiro de Geografia e Estatística apud Huertas (2009)

Obs.: (1) Nome do município, estado da federação onde se localiza e ano de criação. (2) Valor adicionado da agropecuária (VAA), indústria (VAI), serviços (VAS), impostos (IMP) e valor nominal (NOM) - Dados de 2005. (3) Dados de 2007 


\section{PARA ALÉM DO ECONÔMICO, A CENTRALIDADE POLÍTICA}

Nos últimos anos, devido à expansão das frentes econômicas e ao intenso processo de urbanização, notadamente na Amazônia Oriental, várias cidades que apresentaram um novo dinamismo econômico alçaram-se à condição de novas sedes municipais, contribuindo para o processo de fragmentação política do território. O Pará, o Estado de maior dinamismo econômico e populacional da Amazônia Oriental, destaca-se entre aqueles onde esse processo redefiniu a geografia política regional.

Mas não é apenas na escala municipal que a fragmentação política do território se manifesta. Fruto da diferenciação verificada no plano econômico vislumbram-se também recortes e emancipações no sentido de surgimento de novas unidades da federação em nível estadual a partir do território paraense. A diferenciação espacial e territorial tem suscitado propostas de emancipação, do ponto de vista político, por parte de algumas sub-regiōes do estado do Pará. Bem recentemente (ano de 2004) um Projeto de Decreto Legislativo (PDC), o de número 1.217, foi apresentado no Congresso Nacional. Segundo esse projeto, a partir do Estado do Pará surgiriam outros como o do Tapajós e o de Carajás (Quadro 4).

Quadro 4 - Dados socioeconômicos e territoriais de novos estados propostos a partir do território paraense -2004

\begin{tabular}{|c|c|c|c|c|c|}
\hline Estado & $\begin{array}{l}\text { PIB } \\
\text { (R\$ MIL) }\end{array}$ & População & Área $\mathrm{km}^{2}$ & $\begin{array}{l}\text { No de } \\
\text { muni- } \\
\text { cípios }\end{array}$ & Municípios Integrantes \\
\hline Carajás & 8.204 .007 & 907.270 & 228.347 & 29 & $\begin{array}{l}\text { Água Azul do Norte, Bannach, } \\
\text { Bom Jesus do Tocantins, Brejo } \\
\text { Grande do Araguaia, Canaã dos } \\
\text { Carajás, C. do Araguaia, Cumaru } \\
\text { do Norte, Curionópolis, Eldorado } \\
\text { dos Carajás, Floresta do Araguaia, } \\
\text { Itupiranga, Marabá, Nova } \\
\text { Ipixuna, Ourilândia do Norte, } \\
\text { Palestina do Pará, Parauapebas, } \\
\text { Pau D’Arco, Piçarra, Redenção, } \\
\text { Rio Maria, Santa Ma. Das } \\
\text { Barreiras, Santana do Araguaia, } \\
\text { São Domingos do Araguaia, São } \\
\text { Félix do Xingu, São Geraldo do } \\
\text { Araguaia, São João do Araguaia } \\
\text { Sapucaia, Tucumã, Xinguara }\end{array}$ \\
\hline Tapajós & 3.743 .117 & 844.687 & 392.947 & 20 & $\begin{array}{l}\text { Alenquer, Almerim, Aveiro, } \\
\text { Belterra, Brasil Novo, Curuá, } \\
\text { Faro, Juruti, Medicilândia, Monte } \\
\text { Alegre, Óbidos, Oriximiná, } \\
\text { Placas, Porto de Moz, Prainha, } \\
\text { Rurópolis, Santarém, Terra Santa, } \\
\text { Uruará, Vitória do Xingu }\end{array}$ \\
\hline
\end{tabular}

Fonte: BOUERI, R. "Custos de funcionamento das unidades federativas brasileiras e suas implicaçóes sobre a criação de novos estados". Textos para discussão no. 1367, Rio de Janeiro, IPEA, dez. 2008 
Os estados sugeridos possuem grande extensão territorial e uma população relativamente reduzida. As cidades propostas como sedes estaduais são as mesmas que nas últimas décadas têm assumido a centralidade no contexto regional. Trata-se de uma mediação, do ponto de vista político, dada à importância e centralidade daquelas cidades tendo em vista a descentralização econômica no território estadual. Suas condições de fóruns regionais de decisōes políticas e debates em torno de questôes que afetam diretamente a sub-região em que se inserem (Pereira, 2004), tornam essas cidades importantes espaços de centralidades econômicas e políticas em face da projeção dessas sub-regióes, que se alçam à condição de novos estados da federação.

As elites locais não se resumem mais às oligarquias tradicionais, mas incluem novos agentes, que chegaram com as novas frentes de expansão, inclusive grandes empresários, pecuaristas etc., como no caso sudeste paraense (Emmi, 1987), ou dos sojeiros, como no caso do oeste paraense. Esses novos agentes têm comandado a proposta de emancipação e difundido a propaganda de criação desses mesmos estados, com sedes em Marabá (Estado de Carajás), no sul/sudeste do Pará, e Santarém (Estado do Tapajós), no oeste paraense.

Nesses casos busca-se associar uma identidade regionalista na escala sub-regional a um discurso de melhor distribuição das arrecadaçóes e de um possível redirecionamento do desenvolvimento econômico regional. Trata-se, entretanto, muito mais da formalização política de novas territorialidades já desenhadas, responsável por dar apoio ao poder local que se redefiniu nas últimas décadas e que exerce uma grande influência política no interior do território paraense (Trindade Jr.; Pereira, 2007).

Ademais, a presença de grandes projetos econômicos ou de importantes atividades econômicas em expansão sob sua área de influência revelam uma relativização do papel de Belém, uma das metrópoles regionais, frente às cidades médias, especialmente Marabá e Santarém, que definem novos papéis no contexto da participação econômica da Amazônia oriental, e especialmente do Estado do Pará.

Associada a isto está a situação de perda da condição de Belém de ser a única porta de entrada da região, que foi dominante até a abertura de rodovias na Amazônia, responsável por fragilizar a função portuária e a importância dos rios como principais vias de circulação na região. As tentativas de emancipação política, notadamente do sul/sudeste e do oeste paraense revelariam, portanto, essa situação de "fragilidade" de Belém também do ponto de vista político.

Nesse caso, as novas lideranças políticas do Estado do Pará, localizadas fora da área de influência imediata de Belém e fortalecidas economicamente pelas frentes de modernização recentes no interior da Amazônia, conforme acontece no caso das sub-regiões aqui consideradas, postulam a formação de novos estados da federação; portanto, com maior autonomia dentro do território nacional e sem subordinação política a Belém.

Esse processo resulta de uma espécie de balcanização política dentro do território paraense, já definida em termos não formais, e de uma estratégia de afirmação dos poderes locais em nível sub-regional. Tais forças políticas se reforçam pela importância assumida pelas cidades médias; daí a recorrente mobilização para fins de autonomia estadual assentadas nessas bases territoriais sub-regionais e com referência de centralidade em cidades médias, que, nas últimas décadas, passaram a expressar importante destaque do ponto de vista da centralidade econômica, conforme já mencionado.

Ideias de que "Belém explora Marabá" ou de que as arrecadações de Santarém não são devidamente repassadas e investidas no plano local devido ao controle metropolitano, definem um sentimento de perda, de exploração e de exclusão, que acaba por caracterizar 
uma dada identidade territorial de base sub-regional, responsável por mobilizar ações emancipatórias. O discurso apresentado nesse nível leva a crer que é na instância territorial almejada - um novo estado da federação - que os problemas apresentados na escala mais imediata serão resolvidos. Trata-se, como nos diz Sack (1986), de designar a solução desses problemas para a escala errada, pois é sabido que, no caso amazônico, é na produção do espaço regional e de sua articulação com outras escalas externas que eles se constituem. Ademais, a apropriação dos movimentos de emancipação por parte das lideranças políticas e projetados a partir das cidades que lhes servem de base - as cidades médias - associa-se, igualmente, ao potencial eleitoral dessas localidades, definido pela dinâmica mais recente de produção do espaço regional amazônico.

Presencia-se, com isso, a emergência ou fortalecimento de forças políticas setorizadas e balcanizadas no interior do espaço amazônico, configurando propostas de partilhas territoriais na geografia eleitoral regional. Isso acontece na medida em que passa a existir um maior crescimento relativo dos eleitores nos novos espaços de povoamento induzidos por novas dinâmicas econômicas. Por outro lado, faz-se interessante analisar quais têm sido as respostas a essas intenções, de uso político do território, por parte do próprio Estado. Tomando como exemplo essa escala sub-regional, várias têm sido as estratégias que se têm procurado usar diante das perspectivas de fragmentação do território definidas pelos novos agentes estabelecidos na Amazônia Oriental, e mais especificamente ainda no território paraense.

Uma delas aconteceu quando então, tendo em vista a possibilidade de construção da Usina Hidrelétrica de Belo Monte, no rio Xingu, foi sugerida a transferência da capital de Belém para aquela localidade. Tratava-se da construção de uma nova capital, nos moldes da estratégia geopolítica de construção de Brasília. Essa parecia ser uma resposta das elites políticas sediadas em Belém no sentido de definição de um novo pacto de base territorial visando à recuperação do controle político em sub-regiôes que foram fortemente afetadas pelas frentes de expansão econômica, a exemplo daquelas cortadas e/ou influenciadas pela rodovia Transamazônica, como é o caso de Marabá e Santarém.

Buscava-se, com isso, arrefecer os ânimos em relação a três propostas de emancipação política, a do estado de Carajás (com capital em Marabá), a do estado do Tapajós (com capital em Santarém) e a do estado do Xingu (com capital em Altamira), dado o potencial dessas cidades e de suas respectivas regiōes, responsáveis por colocar em xeque as forças políticas sediadas em Belém. Assim sendo, a construção de uma nova capital, mais centralizada do ponto de vista da disposição física do território, passou a representar o enfrentamento do discurso de canalização dos recursos econômicos originados nessas sub-regiōes para Belém, sob o pretexto da descentralização política das decisões. A importância histórico-cultural de Belém e a força política ainda sediada nessa cidade, entretanto, fizeram abortar essa ideia.

Outra estratégia foi assumida mais recentemente pelo governo estadual na gestão do Partido dos Trabalhadores (2007-2010), dizendo respeito a um novo formato de pacto territorial que pressupunha a discussão participativa da distribuição dos recursos e dos investimentos territoriais e sociais. Esse formato, denominado de Planejamento Territorial Participativo do Estado do Pará (PTP-PA), consistiu em uma espécie de "orçamento participativo" em nível estadual, que primava pela participação social e pela descentralização da tomada de decisão por parte do governo estadual. Neste caso, a contra-ação se colocava a partir de uma nova estratégia de gestão que desconstruía o discurso da centralização das decisóes e da canalização de recursos e investimentos em direção à capital. O recorte 
territorial proposto, nesse caso, estava baseado em uma estratégia que buscava levar em conta a nova dinâmica espacial e os graus de urbanização do território e de distribuição populacional no espaço, sugerindo, portanto, a não necessidade de novos recortes político-administrativos.

Tanto em uma quanto em outra proposta, a centralidade política das cidades parece estar presente no processo de gestão do território e faz essas mesmas cidades tornarem-se, do ponto de vista territorial, protagonistas de projetos políticos, como espaços relacionais que são, das proposições de emancipação em curso. Revelam-se, portanto, correlações de forças que têm em vista o controle de tributos, de recursos e de eleitores, cuja mediação é dada a partir da dimensão territorial, como uma forma de rearranjo de antigas estruturas sociopolíticas e espaciais que foram alteradas pela presença de novos agentes econômicos e pelo incremento de novas atividades econômicas no interior da Amazônia Oriental.

Essa é a razão pela qual a gestão do território passa a estar no jogo das estratégias do Estado, dos grupos sociais, das instituições e dos agentes econômicos, pressupondo ações que objetivam a criação e o controle da organização do espaço e, por meio disso, viabilizar a existência e a reprodução das novas relações que se fazem presentes nessas sub-regiōes da Amazônia, caracterizadas pelo dinamismo econômico, pela alteridade e pelas tensôes de base territorial.

\section{CONSIDERAÇÕES FINAIS}

$\mathrm{Na}$ Amazônia, a cidade média pode ser considerada como um elemento relativamente recente na rede urbana regional. $\mathrm{O}$ sentido dado a essas cidades na análise aqui realizada as coloca como centros urbanos regionais e, portanto, como espaços relacionais, no sentido de que só podem ser compreendidos a partir dos contextos em que se inserem (Harvey, 1980). Não se confundem, portanto, nem com as cidades intermediárias, que sempre estiveram presentes na estrutura da rede urbana, e nem com as cidades de porte médio, caracterizadas a partir de um patamar demográfico mínimo.

Como centros urbanos regionais, assumem importantes centralidades, devido ao conjunto de fluxos que definem um caráter centrípeto a determinados pontos do território, relativamente bem articulados pelas novas vias de circulação, mas igualmente pela capacidade de oferecer infraestrutura, serviços, mão de obra e mercadorias de um modo geral; fatores estes que são fundamentais à reprodução econômica em nível territorial.

Normalmente associadas à modernização econômica e à boa qualidade de vida, na Amazônia, as cidades médias tendem a se diferenciar daquelas outras onde as relações capitalistas já se mostram mais consolidadas e não se apresentam como espaços de expansão das novas relações capitalistas. É nesse sentido que os fixos modernos, no caso de cidades amazônicas como Santarém e Marabá, parecem assumir menos importância que a capacidade de gerar e de possibilitar a dinâmica dos fluxos; elementos cruciais na definição das centralidades urbano-regionais aqui consideradas. Para além da dimensão econômica, entretanto, outras centralidades se fazem presentes, como aquelas que evidenciam novas relações de poder no espaço regional, denominadas, para efeitos de nossa análise, de centralidades políticas.

Estas reflexões buscam contribuir para pensar as cidades médias no espaço brasileiro contemporâneo, considerando particularidades regionais e possibilidades de reconhecer formas urbanas diversas, tendo em vista a produção desigual e diferenciada do espaço 
Saint-Clair Cordeiro da Trindade Júnior é Professor Associado III da UFPA; pesquisador do CNPq. Email: stclair@ufpa.br

Artigo recebido em junho de 2011 e aprovado para publicação em agosto de 2011.
C I D A D E S M É D I A S N A A M A Z Ô N I A O R I E N T A L

geográfico. Mais importante ainda para a reflexão teórica, e pouco importando a denominação que se queira dar a esse nível de cidade, são os processos que podem ser evidenciados na análise dessas dinâmicas regionais, associando-os à importância assumida por esses expressivos núcleos urbanos de destaque regional.

Conforme já demonstrado, tais cidades não podem ser definidas somente pelo patamar demográfico - o que parece ser consenso nas discussões mais atuais. Da mesma forma, parece pouco esclarecedor associá-las mecanicamente à modernização do território, que decorre em grande parte dos processos de desconcentração econômica. Insistir nesse empreendimento sugere caminhar para uma teorização sobre essas cidades com base em referências espaciais etnocêntricas. Além disso, outras dimensões da centralidade devem ser levadas em conta, no sentido de ultrapassar o perfil econômico normalmente mobilizado para compreender os papéis dessas cidades. Aqui a dimensão política foi discutida e articulada à dimensão econômica para tratar a condição de Marabá e Santarém como cidades médias da Amazônia Oriental brasileira, mas mesmo outras dimensōes da realidade espacial e territorial podem ser consideradas, a exemplo daquelas que envolvem elementos da cultura e da formação histórico-social dessas cidades, que revelam, igualmente, novas expressões do regionalismo, responsáveis por alimentar os pactos territoriais que dão sentido às propostas de fragmentação política.

\section{REFERÊNCIAS BIBLIOGRÁFICAS}

BECKER, B. Amazônia. São Paulo: Ática, 1990. (Série Princípios). . Amazônia: geopolítica na virada do III milênio. Rio de Janeiro: Garamond,

2004.

BOUERI, R. "Custos de funcionamento das unidades federativas brasileiras e suas implicações sobre a criação de novos estados”. Textos para discussão no. 1367, Rio de Janeiro, IPEA, dez. 2008.

BROWDER, J.; GODFREY, B. Rainforest cities: urbanization, development and globalization of the Brazilian Amazon. New York: Columbia University Press, 1997.

CORRÊA, R. L. "A periodização da rede urbana da Amazônia". Revista Brasileira de Geografia, Rio de Janeiro, v. 4, n. 3, p.39-68, jul./set. 1987.

EMMI, M. F. A oligarquia do Tocantins e o dominio dos castanhais. Belém: UFPA/NAEA, 1987.

HARVEY, D. A justiça social e a cidade. São Paulo: Hucitec, 1980.

GUERRA, G. A. D. "Apropriação, uso da terra e desenvolvimento territorial na Amazônia”. In: ROCHA, G. M.; MAGALHÃES, S. B; TELSSERENC, P. Territórios de desenvolvimento e açōes públicas. Belém: Edufpa, 2009. p.185-205.

HUERTAS, D. Da fachada atlântica à imensidão amazônica: fronteira agrícola e integração territorial. São Paulo: Annablume, 2009.

MACHADO, L. O. "Urbanisation et marché du travail en Amazonie brésilienne". In: DIAS, L. C.; RAUD, C. (Orgs.). Villes et région au Brésil. Paris: L'Harmattan, 2000, p.165-91.

MAGNANO, A. A. "A estrutura do espaço regional". In: IBGE. Geografia do Brasil: região norte. Rio de Janeiro, 1989. v. 3 p.275-307.

PEREIRA, J. C. M. Importância e significado das cidades médias na Amazônia: uma abordagem a partir de Santarém (PA). Belém, 2004. Dissertação (Mestrado em Planejamento 
do Desenvolvimento) - Núcleo de Altos Estudos Amazônicos, Universidade Federal do Pará.

PORTO-GONÇALVES, C. W. Amazônia, amazônias. São Paulo: Contexto, 2001.

RIBEIRO, M. A. A complexidade da rede urbana Amazônica: três dimensões de análise. Rio de Janeiro, 1998. Tese (Doutorado em Ciências) - Programa de Pós-Graduação em Geografia, Instituto de Geociências, Universidade Federal do Rio de Janeiro.

ROCHA, G; LIMA, A. “A criação de novos municípios e o ordenamento territorial no Estado do Pará”. In: ROCHA, G. M.; MAGALHÃES, S. B; TELSSERENC, P. (Orgs.) Territórios de desenvolvimento e açôes públicas. Belém: Edufpa, 2009. p.209-30.

SACK, R. D. Human territoriality: its theory and history. Cambridge: University Press, 1986.

SANTOS, M. A urbanização brasileira. São Paulo: Hucitec, 1993. . A natureza do espaço: técnica e tempo, razão e emoção. São Paulo: Edusp, 1996.

SPOSITO, M. E. B. "Novas formas comerciais e redefinição da centralidade urbana". In: ___ (Org.) Textos e contextos para a leitura geográfica de uma cidade média. Presidente Prudente: UNESP, 2001a. p.235-53.

SPOSITO, M. E. B. "As cidades médias e os contextos econômicos contemporâneos". In: __ (Org.) Urbanização e cidades: perspectivas geográficas. São Paulo: UNESP, 2001b. p.609-43.

TAVARES, M. G. O município no Pará: a dinâmica territorial municipal de São João do Araguaia-PA. Rio de Janeiro, 1992. Dissertação (Mestrado em Geografia) - Instituto de Geociências, Universidade Federal do Rio de Janeiro.

TRINDADE JR., S. C.; PEREIRA, J. C. C. "Reestruturação da rede urbana e importância das cidades médias na Amazônia oriental”. In: SPOSITO, M. E. Cidades médias: espaços em transição. São Paulo: Expressão Popular, 2007. p.313-42.

TRINDADE JR., S. C.; RIBEIRO, R. "Marabá: novos agentes econômicos e novas centralidades urbano-regionais no sudeste paraense". In: TRINDADE JR., S. C. et alii (Orgs.). Pequenas e médias cidades na Amazônia. Belém: ICSA/UFPA, 2009. p.333-59.

VICENTINI, Y. Cidade e história na Amazônia. Curitiba: Ed. da UFPR, 2004.

VILLAÇA, F. Espaço intraurbano no Brasil. São Paulo: Nobel, 1998.

A B S T R A C T This paper presents elements of the urban-regional centrality of middle-size cities in the Brazilian Amazonia and discusses the role of these cities in a context of territorial restructuring. For that analysis it is considered conceptual differences between "center" and "centrality", as well as between "flux" and "fix" are considered. The empirical references of the analysis are two cities located in the eastern Amazonia-Maraba and Santarém. The study approaches the importance of these cities for the regional production of space and considers historical elements of the territorial formation of Brazilian Amazonia, as well as statistical data and documental information about that region and its urbanization process. The analysis finishes whith the discussion of the role played by middle cities in the Amazon region and its political centrality in a context of spatial re-arrangement, of emergence of new political interests and of political territory division intentions.

K E Y W O R D S Middle-size cities; Eastern Amazon; centrality; territorial division. 